\title{
The Evolved Functions of Procedural Fairness: An Adaptation for Politics
}

\author{
Troels Bøggild \\ Department of Political Science \\ Aarhus University, Denmark \\ E-mail: tboeggild@ps.au.dk
}

\author{
Michael Bang Petersen \\ Department of Political Science \\ Aarhus University, Denmark \\ E-mail: michael@ps.au.dk
}

Chapter accepted for publication in Todd K. Shackelford \& Ranald D. Hansen (Eds.), The Evolution of Morality, New York: Springer. 


\begin{abstract}
Politics is the process of determining resource allocations within and between groups. Group life has constituted a critical and enduring part of human evolutionary history and we should expect the human mind to contain psychological adaptations for dealing with political problems. Previous research has in particular focused on adaptations designed to produce moral evaluations of political outcomes: is the allocation of resources fair? People, however, are not only concerned about outcomes. They also readily produce moral evaluations of the political processes that shape these outcomes. People have a sense of procedural fairness. In this chapter, we identify the adaptive functions of the human psychology of procedural fairness. We argue that intuitions about procedural fairness evolved to deal with adaptive problems related to the delegation of leadership and, specifically, to identify and counter-act exploitative leaders. In the chapter, we first introduce the concept of procedural fairness, review extant social psychological theories and make the case for why an evolutionary approach is needed. Next, we dissect the evolved functions of procedural fairness and review extant research in favor of the evolutionary account. Finally, we discuss how environmental mismatches between ancestral and modern politics make procedural fairness considerations even more potent in modern politics, creating a powerful source of moral outrage.
\end{abstract}

Keywords: procedural fairness, procedural justice, evolutionary psychology, politics, dominance, leadership, strategic moralization 
Politics is the process of determining resource access (Petersen 2015). In a classical definition, the political scientist, David Easton (1953), thus defined politics as the process of determining the "authoritative allocation of values for a society." In more plain terms, another classical definition described politics as about "who gets what" (Lasswell 1950). These definitions highlight that politics is ultimately about outcomes: who gets a resource and who does not. Some researchers of politics have taken this to imply that outcomes are all people care about in politics. As Ulbig (2002, p. 793) notes, the traditional notion has been that "when people get what they want they do not care how they get it". Popkin (1991, p. 99), for example, holds that people "care about ends not means; they judge government by results and are ... indifferent about the methods by which the results were obtained".

A brief look at the reporting of political news, however, makes it clear that outcomes are just one part of what receives attention in politics. Reports on the substances of political policies (who is affected by the policies and how) are often outnumbered by reports on the political process that leads to the policies (see Patterson 1994; Aalberg et al. 2011): who are the key actors, why do they promote or oppose a specific policy, what are their interests, what is their strategy for achieving those interests? Research has documented that such a focus is, at least in part, demand driven: people crave information about the process leading to outcomes and the strategic aspects involved (Smith et al. 2007; Trussler \& Soroka 2014). This appetite for information about what goes on behind the scenes of political outcomes extends even to the personal lives of politicians: who are they, whom are they personally affiliated with, and do they practice what they preach politically? This latter observation illustrates an important point: people's political interest not only extends beyond a narrow interest in the substance of policies; this interest is also moral in nature. Public outrage and strong moral condemnation meets the hypocritical and self-interested politician (Cappella \& Jamieson 1996; Hibbing \& Alford 2004; Bøggild 2014). 
The observation that people are morally preoccupied with not just political outcomes but also the processes leading to these outcomes is supported by decades of research in social psychology. This research has predominantly focused on the perceived legitimacy of decisions in the context of everyday life rather than politics. In the contexts of everyday life, it has been demonstrated (1) that people are interested in many more features of decisions than outcomes and (2) that this interest is, in part, moralistic (Charness \& Levine 2007; Falk et al. 2008; Ong et al. 2012; van den Bos et al. 1998; Tyler 1990). Many of these studies have been organized around the concept of procedural fairness, which highlights both the orientation towards procedures and the moral nature of this orientation. Empirical findings include that people view decisions as more legitimate if they were allowed to voice their opinions before the decision was made, if the decision maker was impartial and lacked personal interest in the decision, and if all relevant parties were included in the decisionmaking process (e.g. Tyler 1990). The overall finding that people care not only about the substance and outcomes of decisions but also about how decisions come about when evaluating group leaders and their decisions has been characterized as one of the most replicated findings in social psychology (van den Bos et al. 1998, 1449). Recent empirical studies have extended the concept of procedural fairness to politics, directly confirming the observation that people care about political process as well as political outcomes. It has been shown that whether political institutions follow fair procedures is an important determinant of citizens' trust in national-level political and legal institutions and political representatives and also that political decisions that emerge from fair procedures receive greater public support (Tyler 1994; Grimes 2006; Ulbig 2008; Bøggild 2014).

In this chapter, we ask: Why are people morally preoccupied with features of the processes leading to political outcomes rather than just with the outcomes themselves? Although the concept of procedural fairness has received widespread attention across the 
social sciences over the past four decades, it remains contested at the theoretical level. As argued by Smith et al. (2007, p. 288), while the empirical support for people's attention to procedural fairness is steadily growing, "the absence of a theoretical explanation becomes ever more glaring". More specifically, existing theoretical frameworks have been criticized for being too narrow in their scope and for providing proximate accounts that assume rather than explain why procedural fairness matters (Hibbing \& Theiss-Morse 2008). In reference to the distinction between ultimate ("why") and proximate ("how") explanations (Scott-Phillips et al. 2011), we here seek to provide an ultimate explanation of why human moral judgments about decisions are oriented towards the procedural aspects of the decision. To achieve this, we part with previous work on procedural fairness in social psychology in two ways: First, for reasons developed below, we utilize an evolutionary biological framework and dissect the fitness benefits of psychological systems for procedural fairness for humans. Second, we provide an explanation that puts politics front and center. The psychology of procedural fairness, we suggest, evolved specifically to deal with key problems related to politics, such as the formation of hierarchies and the delegation of leadership. Part of the failure of previous theoretical accounts, we suggest, emerges because these accounts have not taken their point of departure in political clashes of interest. Notions of procedural fairness are crucial parts of human nature as a political animal and, to understand the ultimate function of these notions, they need to be analyzed in the context of politics. ${ }^{1}$

The chapter proceeds in four steps. The first section reviews existing theoretical models of procedural fairness and the main points of criticism that have been launched against them. The second section makes the case for an evolutionary approach to procedural fairness, emphasizing the role of politics in human evolution and fleshes out the adaptive problem that procedural fairness evolved to accommodate: exploitative political leaders. The third section

\footnotetext{
${ }^{1}$ We do not mean to imply that extant (or future) research on procedural fairness conducted in legal, managerial or educational settings is not important. Rather, we view these contexts as also political in the sense that the decision-making processes manage clashes of interests between opposing parties.
} 
specifies how notions of procedural fairness serve two distinct purposes in terms of (1) detecting exploitative tendencies in leaders (i.e. a diagnostic function) and (2) actively counteracting and restricting the potential for exploitation in political processes (i.e. a bargaining function). This section also reviews a range of existing empirical evidence in procedural fairness research from social psychology consistent with this account. The fourth section describes how the psychological system for procedural fairness influences modern political attitudes and behaviors - and why mismatches between the circumstances of ancestral and modern, mass-level politics might cause this influence to be even more powerful today than ancestrally.

\section{Procedural Fairness: Existing Findings and Theory}

Over the last four decades, research on procedural fairness in social psychology has provided extensive evidence that people look to certain information about how decisions come about when evaluating group authorities and the decisions they implement (Thibaut \& Walker 1975). This literature has uncovered several criteria for what constitutes a widely perceived legitimate or "fair" decision-making process (Leventhal 1980; Tyler 1990). The literature has also demonstrated that evaluations of the decision-making process (procedural fairness) are distinct from evaluations of the decision outcomes (e.g., distributive fairness, see Colquitt, 2001) and, hence, require a distinct set of explanations.

Three studies can serve as illustrations of the criteria people used when making judgments of procedural fairness. A seminal illustration comes from Tyler's (1990) book, Why People Obey the Law. Through panel analysis it is demonstrated how people who had been in recent contact with the legal system were more likely to comply with and accept an unfavorable verdict when the judge adhered to certain procedural criteria such as allowing 
them to voice their opinions, appeared impartial and unbiased and included all relevant parties in the decision-making process - even after controlling for the outcome of the decision.

In another illustrative study, De Cremer \& Knippenberg (2003) had subjects play a public goods game in which subjects were to decide how much of their own endowment they wanted to contribute to a public pot. If the public pot reached a certain size the pot would be doubled and then divided among all players, creating an incentive to contribute to providing this public good but also an incentive to free-ride and let others make the necessary contributions. Each group of subjects played a total of six contribution rounds and was assigned a group leader deciding throughout the game which subjects deserved a share of the public pot. The authors manipulated whether the group leader allowed subjects to voice their opinions (as opposed to denying voice) before deciding how to divide the public pot and whether the group leader had accurate (as opposed to inaccurate) information about subjects' contribution records to base his decision on. As expected, a group leader allowing voice in the decision-making process and basing the decision on accurate information increased subjects' subsequent contribution levels, even after controlling for the payoffs received.

In a final illustrative study, Ramirez (2008) investigated through a survey experiment the effects of media coverage concerning procedural fairness of the Supreme Court on public support for the Court and the individual justices. Specifically, the author had subjects read a news article and manipulated whether the Court was portrayed as allowing all parts to voice their opinions, was representative of the American people and was objective and impartial in their decision-making. As expected, subjects expressed higher levels of support for the Court and its justices when these procedural criteria were met.

These studies illustrate the findings in the literature on procedural fairness. Other studies have demonstrated how procedural fairness matters beyond the legal context, 
including in educational (Tyler \& Caine 1981), managerial (Lavelle et al. 2009), and political (Tyler 1994; Bøggild 2014) settings. Figure 1 reports six widely considered procedural criteria. The list is not exhaustive and the conceptual terminology sometimes varies from study to study within social psychological literature. Nonetheless, there is general agreement that the listed procedural criteria are of key importance when people make moral evaluations of decisions.

\section{FIGURE 1 ABOUT HERE}

To account for why people pay attention to such features of the decision-making process when evaluating decision-makers and their decisions, research in social psychology has offered three different theoretical accounts. First, early work adopted an instrumental model of procedural fairness, holding that people insist on procedural fairness to gain control over and attain the best possible outcome (Thibaut \& Walker 1975). For example, it is argued that people prefer having a voice in decision-making processes because it serves as a means of control over the outcome. This model has been criticized for being too narrow in its scope and for disregarding the normative or non-instrumental motivations related to procedural fairness (Tyler 1990). For example, studies have demonstrated how people care about being granted voice even after a decision is made, which seems beyond the explanatory range of the instrumental model (Lind et al. 1990).

Second, to accommodate these shortcomings Tom Tyler and colleagues proposed the relational model of authority (Tyler \& Lind 1992), holding that people's attention to procedural fairness stems from a desire to construct and uphold a social identity. From this perspective, the individual is highly vigilant about how decisions come about because it provides him with a clear indication of the extent to which the group and especially its 
authority figure(s) regard him as an equal and valuable group member (Lind \& Tyler 1988; Tyler \& Lind 1992). When information on procedural fairness signals that authorities do not appreciate the status and standing of the individual (e.g., by not allowing voice or being partial), it responds with decreased levels of trust in authorities and compliance with decisions. For example, in favor of this relational account, studies have demonstrated how experiencing unfair procedures also lowers self-esteem of the individual (Koper et al. 1993; De Cremer et al. 2005). Critics, however, have argued that the relational model does not explain why procedural fairness matters in large-scale settings beyond personal interactions. For example, it seems less straightforward why people would look to information on procedural fairness of national courts or governments to determine whether they are valued group members and construct a social identity on this basis (Leung et al. 2007). Moreover, scholars have questioned whether the relational model constitutes a theory at all. Simply holding that people have a need for constructing a social identity and that decision-making processes somehow provide relevant information in this regard, it is argued, is merely a statement or at best a description without an underlying theoretical logic (Smith et al. 2007). These critics hold that "Tyler has won the empirical battle but there is no victor in the theoretical war" (Hibbing \& Theiss-Morse 2008, p. 125).

Third, Fairness heuristic theory (Van den Bos et al. 1997) constitutes the most recent theoretical framework in procedural fairness research. According to this framework, people often lack relevant information in evaluating and making sense of the outcomes they receive from group decisions. For example, people are often faced with situations in which they are uncertain about the trustworthiness of decision makers and whether their own outcome is fair compared to outcomes of others. Fairness heuristic theory holds that under such uncertainty, people compensate by applying information on procedural fairness as a heuristic in evaluations of decision outcomes (Brockner \& Wiesenfeld 1996; Van den Bos et al. 1998). In 
support of this model, Van den Bos et al. (1997) have demonstrated how information on procedural fairness has a larger impact on evaluations of decisions when subjects only know their own outcomes and not the outcomes of others compared to when the outcomes of all subjects are known. Yet, fairness heuristic theory has been subjected to the same criticism levelled against the relational model of authority. This framework focuses only on the cognitive processes related to how people apply information on procedural fairness and does not address why such information, over other types of information, helps the individual cope with uncertainty (van Prooijen 2008, 36). That is, "what precisely it is about procedural fairness that makes it useful under conditions of uncertainty remains unclear" (Gonzalez \& Tyler 2007, p. 94).

In sum, although existing models have generated important insights on the effects of procedural fairness, they remain contested at the theoretical level. Our view is that each of these theoretical models has important merits and that an integrative account, which is immune to the criticism leveled against the models, can be formulated through further theorizing. Specifically, we argue that criticisms of the previous models can be accommodated by considering where preferences for procedural fairness ultimately stem from. Despite extensive scholarly attention to the concept of procedural fairness, key researchers in this literature have noted that "...little is known about the origins of procedural preferences" (Tyler 1990, p. 109) and that what is needed is "a deeper account of the reasons people are so concerned with process variables" (Smith et al. 2007, p. 288). Deep, originoriented accounts are important in their own right but they are also important because we become better able to understand how something works when we know why it exists. That is, by knowing why people care about procedures, we inevitably learn more about how and when we care about them. 


\section{Where to Look for 'Why'? Evidence for the Relevance of Biological Evolution}

In this chapter, we seek to provide an ultimate explanation of why human moral judgments about decisions are oriented towards the procedural aspects of the decision. In emphasizing the "ultimate" nature of our explanation, we refer to the distinction between ultimate ("why") and proximate ("how") explanations (Scott-Phillips et al., 2011). Ultimate explanations of a trait involve explaining why this given trait (here, moral attention to procedures) rather than alternative traits (e.g., moral attention to outcomes only) exist in a population.

Ultimate explanations are often functional explanations. That is, the trait is explained with reference to the function it serves within a population. Two types of functional explanations are common: Explanations of cultural evolution and explanations of biological evolution. Theories of cultural evolution explain a trait with reference to the function it serves within a culturally-specific population. In the case of procedural fairness, it could be that such norms help sustain democratic regimes. Theories of biological evolution explain the existence of a trait with reference to the fitness benefits it conferred ancestrally. In determining whether a trait is the effect of cultural evolution, biological evolution (Cosmides \& Tooby 1997) or both (Boyd \& Richerson 1988), one key question relates to how widespread the trait is: ${ }^{2}$ What is the appropriate population? Are norms of procedural fairness specific to a few cultures or are they cultural universals? If the former, it lends credence to explanations oriented towards cultural evolution; if the latter, it lends prima facie credence to explanations oriented towards biological evolution. This is certainly not everything that needs to be established to determine the relevance of either explanatory type (Cosmides \& Tooby 1997). But it is an important first step.

\footnotetext{
${ }^{2}$ Although, see Tooby and Cosmides' (1992) notion of evoked culture that is not culturally universal but still the product of biological evolution.
} 
The evidence from psychological research is unequivocal. The effects of procedural fairness are pan-cultural, having been replicated in non-democratic and non-Western countries such as Japan (Takenishi \& Takenishi 1992), Singapore (Khatri et al. 2001), India (Pillai et al. 2001; Platow et al. 2013), South Africa (VanYperen et al. 2000), Russia (Giacobbe-Miller et al. 1998) and China (Wilking 2011). Moreover, anthropological studies suggest that even simple hunter-gatherer societies entirely excluded from modern civilizations evaluate leaders by means of procedural fairness standards such as voice and impartiality (Meggitt 1978; Boehm 1993; see also Van Vugt et al. 2008). As concluded by Krislov (1991, 237), although procedural fairness may be practiced in somewhat different ways across cultures, "the generic desire for it may be much broader, even universal".

These observations provide a prima facie case that intuitions about procedural fairness need to be explained not with reference to culturally-specific processes but with reference to processes of biological evolution - that these intuitions constitute an ingrained part of human nature. The conclusion that procedural fairness norms emerge from specialized, deep-seated psychological processes is further sustained by evidence from two disciplines: developmental psychology and affective neuroscience. Developmental studies have shown that children of a very young age possess a sophisticated understanding of procedural fairness and react strongly to perceived unfair procedures (Fry \& Corfield 1983; Hicks \& Lawrence 1993). Gold et al. (1984), for example, find that 6-7 year old children evaluate adult authorities by means of procedural fairness standards and easily detect and respond to unfair treatment. Studies using techniques from affective neuroscience have furthermore shown that information on procedural fairness yields responses that are highly affective, automatic, and unconscious (Hibbing \& Alford 2004; Weiss et al.1999; see also Ham \& van den Bos 2008), and that these responses rely on distinct parts of the brain that are different from those processing information on distributive fairness (Dulebohn et al. 2009; 
Beugré 2009). These observations on children's and adults' reasoning about procedural fairness suggest that intuitions about procedural fairness emerge naturally as part of normal developmental processes and due to the existence of deep-seated, dedicated psychological mechanisms. Both observations reinforce the suggestion that the psychological mechanisms underlying these intuitions could have evolved through biological evolution (see Hibbing \& Alford 2004; Dulebohn 2009). If so, intuitions about procedural fairness should ultimately be explained with reference to their fitness benefits throughout human evolutionary history and, hence, as products of natural selection.

\section{Adaptive Problems in Politics: The Benefits and Costs of Hierarchies}

A psychological mechanism can evolve by natural selection to the extent the mechanism helps the organism solve an evolutionarily recurrent problem. An adaptive "problem" is anything that has repercussions for the organism's fitness (Tooby \& Cosmides 1992). In such a case, solving the given problem is the mechanism's biological "function". Identifying the particular problem that a mechanism evolved to solve requires an identification of the context in which the mechanism in question is activated.

In the case of the psychology of procedural fairness, there has been no systematic empirical study of its precise domain of application and this is something that is important to explore empirically in the future. Still, an important observation can be made: as illustrated by the three descriptions of social psychological studies of procedural fairness, considerations of procedural fairness generally only become relevant when decisions are made on behalf of others. When people make decisions for themselves it can be asked whether the decisionprocess was rational but not whether it was fair. In this sense, the evolution of the psychology of procedural fairness is narrowly and intimately related to the evolution of politics: the struggle for decision-making power and, ultimately, resources in social groups. 


\section{Politics as a Set of Adaptive Problems}

Over the course of evolutionary history humans have reaped the benefits of living in groups, providing protection against other groups and predatory enemies, higher reproduction rates, and reduced variation in appropriation of food (Foley 1995; Kenrick et al. 2003). Group life, however, also brought challenges, most significantly in terms of social coordination issues like group movement, intergroup competition, and internal conflict resolution and peace-keeping (De Waal 1997; Van Vugt et al. 2008). There are multiple ways to handle such common problems within and between groups and each way entails a different distribution of costs and benefits across individual members. Group life therefore inevitably involves a negotiation about how the spoils of group life should be divided: who should benefit the most and who should pay the greatest costs? Politics is this negotiation about who gets what.

A crucial part of politics is the formation of hierarchies that establishes shared expectations about resource access, with those in the top of the hierarchy getting more. In most animals, these hierarchies are based on dominance: the alpha male is the one who can dominate conspecifics. For many animal species, this is a matter of sheer physical formidability: the biggest and strongest individual in a group can dominate the rest. In contrast, for humans and a few other animals such as chimpanzees, individual formidability does not translate directly into political power. In highly social animals, coalitions of less formidable individuals can be organized to counter any single individual (Boehm 1999; de Waal 2007) and, for humans, political power is mostly a matter of abilities to form and maintain alliances (Whiten \& Byrne, 1997; Von Rueden et al. 2014). As consequence, for the human political entrepreneur, one strategy for forming a stable base of allies is to seek 
prestige rather than dominance (Sidanius \& Pratto 2001; Price \& Van Vugt 2014). ${ }^{3}$ Prestige is status that is granted rather than taken (Henrich \& Gil-White 2001). It is granted on the basis of the individuals' abilities to address the problems confronting potential allies and in that way provide benefits in exchange for the status these individuals receive (Price \& Van Vugt 2014; von Rueden et al. 2014).

According to a steadily growing literature across the social sciences, a sophisticated psychology of leadership and followership has evolved in response to these selection pressures (Tooby et al. 2006; Van Vugt 2006; Van Vugt \& Ahuja 2011). A set of psychological mechanisms — a leadership psychology—evolved to help individuals detect opportunities for prestige-generation. Reciprocally, a set of psychological mechanisms - a followership psychology_evolved to follow and bestow prestige on those individuals (i.e. group leaders) displaying competence in solving crucial adaptive problems (Laustsen \& Petersen 2015; Price \& Van Vugt 2014). The psychology of procedural fairness, we suggest, evolved as part of this larger psychology of followership to ensure that leaders return benefits in exchange for the prestige they are granted.

\section{The Costs and Benefits of Followership}

The dual existence of a psychology of followership and leadership allows leaders and followers to engage in a reciprocal relationship where the costs of coordinating collective decision-making are delegated to a specific individual, the leader. In accepting these costs, the leader would produce public goods in terms of coordinating group efforts and maintaining intra-group peace. In return, the leader would receive high social status and the associated fitness benefits of increased access to material and reproductive resources of the group (Price

\footnotetext{
${ }^{3}$ It should be noted that allies are often also used for dominance. In particular, one group of allies will often seek to dominate other groups of allies (Sidanius \& Pratto, 2001). Still, within each of these groups, one individual will often emerge as more prestigious than others.
} 
\& Van Vugt 2014). In politics, a crucial adaptive problem is therefore to follow and delegate leadership to the right individuals.

A key risk for any follower in a hierarchical, leader-follower relationship is that the delegation of leadership allows the leader to exploit his privileged position to either extract benefits for himself (or his friends or kin) or impose costs on his enemies (Boehm 1999; von Rueden et al. 2014). As argued above, there are multiple solutions to any problem that confronts the collective and each of these solutions impose different benefits and costs on different members of the collective. In this regard, there is often an information asymmetry between followers and leaders. ${ }^{4}$ Often only the leader will have an accurate representation of the space of possible solutions and the costs and benefits associated with each. The delegation of leadership involves the risk that this information asymmetry is utilized to the follower's disadvantage.

More formally, from the perspective of the individual follower, the problem is whether his or her welfare receives sufficient consideration in collective decisions. The problem is not so much if this happens once or twice. The real problem is the accumulation of many small fitness losses over multiple decisions. That is, if the individual's welfare is systematically considered less when decisions are made. In the context of leadership and followership, the crucial factor for whether this happens can be referred to as the leader's Welfare Trade-off Ratio (WTR) toward the individual follower. The terminology of WTRs is an attempt to describe the psychological machinery that evolved to regulate social decisions (Sell et al. 2009; Petersen et al. 2010). When social decisions have repercussions for the welfare of others besides the decision-maker, the decision-maker needs to be able to trade-off

\footnotetext{
${ }^{4}$ In the literature on principal-agent problems, the concept of information asymmetry is used to describe the problems that emerge when followers are implementing the decision of the leader. In such situations, followers sometimes have more information available and, hence, can use the resulting degrees of freedom to implement a decision in a way that this beneficial for the self. Here, we argue that is there is also an information asymmetry when decisions are made (and not just when they are implemented) and this information asymmetry is often to the advantage of the leader.
} 
these repercussions. How much of their own welfare are decision-makers willing to sacrifice for the welfare of another? On the basis of a number of diverse cues such as whether the other is kin, an ally or an exchange partner, humans seem to compute a psychological summary tally, the WTR, for each person in their social network and this tally is accessed during social decisions and guides the relevant welfare trade-offs (Petersen et al. 2012; Tooby et al. 2008). If the decision-maker is willing to trade-off more of his own welfare for the welfare of another person, the decision-maker has a high WTR towards that individual. This psychological tally is relatively stable and, hence, the magnitude of the WTR of individual A for individual B reliably predicts future resource flows from A to B. ${ }^{5}$

If we apply this logic to the relationship between a follower and a leader, it implies that if a follower faces a leader with a relatively low WTR, this leader would potentially select those particular solutions across time that were to the follower's relative disadvantage. This constitutes a fundamental adaptive problem for followership decisions which could result in serious negative feedback-effects on the follower's long-term fitness (Erdal \& Whiten 1996; Haidt 2013; Price \& Van Vugt 2014).

In Jonathan Haidt's words "Individuals who failed to detect signs of domination and respond to them with righteous and group-unifying anger faced the prospect of reduced access to food, mates, and all the other things that make individuals (and their genes) successful in the Darwinian sense" (Haidt 2013, p. 173). Hence, humans should not only possess psychological mechanisms designed to evaluate and follow leaders that are competent but should also have developed a sophisticated psychology for aligning themselves with leaders that hold high WTRs toward the individual and, hence, refrain from exploitation.

\footnotetext{
${ }^{5}$ The literature distinguishes between intrinsic WTRs guiding behavior when no one else oversees the action (determined by kin or friendship relationships) and monitored WTRs guiding behavior when actions are subjected to supervision by others (determined by these others' abilities and willingness to confer benefits and costs on the self upon detection of the self's action) (see Petersen et al. 2010). In the main text of this chapter, we use the term WTR exclusively to refer to monitored WTRs. In footnote 7, we return to the difference between monitored and intrinsic WTRs.
} 


\section{The Adaptive Functions of Procedural Fairness}

We suggest that the psychology of procedural fairness evolved as part of the psychology for countering a leader who (1) devalues the welfare of the self and (2) is willing to act upon it. Specifically, we argue that attention to the decision-making processes of leaders (and not just the outcomes of these processes) evolved to serve two key interrelated functions. First, attention to information on procedures serves a diagnostic function as this information conveys reliable cues to determine the dispositional tendencies and WTRs of group leaders. Second, the moralistic nature of this attention to information on procedures serves a bargaining function: when violations of procedural fairness are detected, they are broadcasted, fueling outrage among and mobilizing others who also fear mistreatment. This latter function helps followers not just detect but also to form political coalitions and actively upregulate leaders' WTRs in collective decisions and hence counter-act exploitation.

\section{Procedural Fairness as a Diagnostic Tool}

Which type of information would have served as reliable indicators of leaders' exploitative tendencies and WTRs over evolutionary history? One possibility is for the individual to evaluate the WTR of a leader towards the self by simply attending to the favorability of decision outcomes generated by the leader. However, evaluating WTRs of a leader by merely attending to the outcomes of decisions adopted by a leader would entail an inadequate and flawed strategy since unfavorable decisions would not necessarily imply a lack of concern for the welfare of the follower (Dubreuil 2011, pp. 32-37). For example, enforcing decisions which in the short-term impose costs on individuals (such as rationing food or, in modern organizations, introducing layoffs or unpopular welfare state retrenchment policies) will at times carry long-term gains. In a similar vein, research on collective action 
and free-riding has demonstrated that people do not make inferences about the WTRs held by others based on the absolute gains they have received from prior interactions with them but on a different set of indicators that more reliably conveys anti-social, cheating dispositions (Delton et al. 2012). In short, evaluating the WTR of leaders by mere attention to decision outcomes would terminate potentially viable relationships with pro-social leaders committed to the welfare of the group and its followers.

The key identification problem is this: when the outcome of a decision enforced by a leader imposes relative costs on a follower, how can the follower identify whether this is caused by a low WTR (predicting further cost-imposition)? To form reliable assessments about the WTR of a leader under such circumstances, the individual will have to rely on other, non-outcome information or cues. This is where procedural information provides important diagnostic information.

The advantage of attending to information on procedural fairness, in contrast to outcomes, is that it helps reveal the dispositional characteristics of leaders and the considerations giving rise to a negative decision. For example, if a leader enforces a collective decision in which he holds a personal, vested interest (i.e. partiality), it sends a reliable signal to followers concerning the leader's attention to their welfare vis-à-vis his own interests in a leadership role. Or, when a follower does not get a voice in collective decisions while others do, it serves as an accurate cue that the leader holds a low WTR toward this individual relative to the welfare of himself and/or other group members. Essentially, when criteria of procedural fairness are violated it signals that the leader does not adhere to the social contract related to prestige (i.e., service in exchange for status) and the relationship drifts from one of prestige (where benefits are granted) to dominance (where benefits are taken without a reciprocal return of service). Consistent with this, anthropological studies have identified a number of leadership behaviors that generate dissatisfaction with the leader, 
and their findings draw a conspicuous parallel to the criteria of procedural fairness theory surveyed above (Furer-Haimendorf 1967; Meggitt 1978; Boehm 1993, 1999; see also Van Vugt et al., 2008). For example, in an extensive ethnographic study of 48 modern huntergatherer foraging societies, Christopher Boehm found that dissatisfaction was triggered among followers by "ineffectiveness, partiality and unresponsiveness in a leadership role" (Boehm 1993, p. 231).

We suggest that a key evolved function of procedural attention is as a prediction tool for the individual follower. By using procedural features to estimate the WTR of the leader towards them, each individual follower seeks to predict whether resources will flow to them in the future if they continue to follow a specific leader. In emphasizing this function, we also argue that alternative evolved functions cannot adequately explain the psychology of procedural fairness. Most importantly, we suggest (1) that the psychology is not designed to determine which leader is best for the group at large (as some might suggest, see Boehm 1999) but instead is designed to help individuals determine which leader is best for themselves; ${ }^{6}$ and (2) that the psychology is not designed to determine the correctness of single decisions but to make predictions about future behavior of the decision-maker. In this way, this function blends the traditional instrumental and relational explanations of procedural fairness: procedural fairness reflects an instrumental attempt to make predictions about the relationship between the leader and a follower. Several features of the structure of procedural fairness judgments are predictable from this evolved function.

First, an extensive literature in social psychology has demonstrated that effects of procedural fairness on evaluations of decision makers and the decisions they implement depend on whether the outcome benefits or harms the individual (referred to as outcome favorability). More specifically, unfair procedures make people lower their evaluations of

\footnotetext{
${ }^{6}$ In terms of selection pressures, the argument that we propose works at the level of individuals and not groups. Moral intuitions are, in other words, strategic in the sense that they serve the interest of the individual and not the group at large (see Petersen 2013).
} 
decision makers and the decision implemented when the outcome generated through such procedures ultimately harms them while they tend to tolerate or overlook the use of unfair procedures when the outcome is favorable (see Brockner \& Wiesenfeld, 1996 for evidence from more than 40 studies). The psychology of procedural fairness is self-centric: it is activated when the self is harmed and used to form representations under these circumstances, in particular. This conclusion is reinforced by studies that show that the effects of procedural fairness also depend on whether the decision affects the individual (i.e. outcome dependence). Two studies have demonstrated that the effects of procedural fairness on evaluations of leaders and their decisions are stronger when enacted by leaders representing the individual's group rather than leaders of other groups (Smith et al. 1998; Tyler et al. 1998). Moreover, van Dijke et al. (2010) have shown that the use of unfair procedures has a larger negative effect on evaluations of the decision-maker and the decision it implements when the decision-maker is powerful and can impose decisions with direct implications on the individual. Finally, Ham and Van den Bos (2008) found that people make faster inferences about procedural fairness when reading about fair and unfair events described in the first person singular compared to descriptions in the third person singular (see also van Prooijen 2008). In sum, these findings provide strong evidence that the psychology of procedural fairness is not designed to estimate whether a leader is mistreating group members at large. If so, procedural features should be attended to independently of the outcome of the individual. Rather, it is specifically designed to activate when the specific follower faces a leader with a potentially low WTR towards the self.

Second, consistent with the notion that procedural fairness criteria are used to make representations about WTRs, a range of social psychological studies show that people use information on procedural fairness to evaluate the trustworthiness and perceived legitimacy of the decision-maker (Tyler \& Degoey 1996; Colquitt 2001). The concept of trust is 
intimately related to evaluations of WTRs since both relate to the individual's belief that another actor, whose behavior can somehow affect the individual's welfare, will attend to the individual's interests and well-being. Some scholars see the connection between procedural fairness and trust in decision-makers as so self-evident that they treat trustworthiness of the decision-maker as a procedural criterion itself or a proxy for perceived procedural fairness rather than as a dependent variable (e.g. Tyler, 1997). As a result, procedural fairness research has instead often looked to the effects of procedural fairness on perceived legitimacy of the decision-maker. For example, procedural fairness is a key determinant of citizens' perceived legitimacy of legal and political institutions including the Supreme Court and the United States Congress (Tyler 1990; Tyler 1994). Moreover, Dulebohn et al. (2009) have demonstrated how experiencing unfair procedures activates social network regions of the brain associated with social and norm violating behavior, which is in line with the proposed account of procedural fairness as a means to evaluate leaders' WTRs.

Third, the effects of procedural information constitute a two-stage process in which the information serves to determine the trustworthiness of leaders and only then gives meaning to the decision implemented (Tyler 1990; Grimes 2006; Bøggild 2014). That is, procedural features are first and foremost used to form representations of the dispositions of the decision-maker and only secondly to form representations of the decision. Research based on fairness heuristic theory has provided further evidence for this notion demonstrating that information on procedural fairness only affects group members' satisfaction with a given decision when the trustworthiness of the decision maker is ambiguous while such information has little effect when trustworthiness of the decision-maker is known and certain (van den Bos et al., 1998). In a similar study, van Dijke and Verboon (2010) demonstrated how information about procedural fairness have no effects when trust in the decision-maker is already high. In sum, these studies indicate that people attend to information on procedural 
fairness to gain a representation of the cooperative dispositions of leaders when these dispositions are ambiguous. Procedural information is not so much attended to in order to evaluate a single decision but is attended to in order to predict future behavior of the leader by evaluating his or her stable dispositions.

Fourth, if a follower uses procedural information to estimate the WTR of a leader towards the self, this information should also influence a broader range of intra-psychic factors such as self-esteem and perceived standing. Conceptually, we can think of self-esteem as a monitoring device of the fitness related success of the individual in terms of maintaining viable social relationships (having social allies/friends, attracting mates etc.) (Leary \& Downs 1995; Leary \& Baumeister 2000). According to Hill and Buss (2006, p. 350), self-esteem functions as “an internal gauge designed to monitor individuals' successes in interpersonal relationships and, particularly the degree to which they are being included or excluded from social groups, and to motivate corrective actions when one's level of social inclusion gets dangerously low." From this perspective, we should expect information on procedural fairness to serve as relevant inputs to this system by cueing whether the individual engages in a viable, profitable relationship with the group leader. Cross-sectional and experimental studies have demonstrated that individuals experiencing unfair relative to fair procedures (e.g., not being allowed to voice their opinions in group decision) report lower levels of selfesteem (Koper et al. 1993; De Cremer et al. 2005). Additionally, procedural fairness influences self-reported well-being (Schmitt \& Dörfel 1999) and mental health of individuals (Beijersbergen et al. 2014).

Fifth, if procedural information is used as a measuring stick to gauge the WTR of a leader, it should also serve to regulate individuals' willingness to sacrifice their own welfare for the group. If unfair procedures signal that a leader is unlikely to let future group resources flow in the direction of the individual it would be an inferior strategy in fitness terms to 
remain committed to and invest in group interests and efforts in the face of such cues. There is substantial evidence that leader behavior that violates procedural fairness criteria lowers the efforts that the individual puts into communal efforts. In particular, studies have demonstrated that procedural fairness is an important component in inducing "organizational citizenship" (Folger \& Konovsky 1989 ; Sweeney \& McFarlin 1993; Tyler \& Degoey 1995; Blader \& Tyler 2003). In the workplace, for example, people experiencing fair procedures are more committed to the company and its goals (Lavelle et al. 2009), report higher job satisfaction (Pillai et al. 1999), and are less inclined to switch jobs (Daileyl \& Kirk 1992). Moreover, scholars have argued that procedural fairness is a key aspect of transformational leadership because fair procedures make group members committed to the goals and success of the group (Pillai et al. 1999). In sum, information on procedural fairness provides the individual with reliable information on the WTR of leaders and their actions and motivates withdrawal from communal efforts when such information indicates that future resources are unlikely to flow in the direction of the individual.

\section{Procedural Fairness as a Bargaining Tool}

When a follower identifies a leader with a low WTR towards the self, this signals an important adaptive problem. Under ancestral circumstances, in which the individual was crucially dependent on social support, it would entail significant fitness benefits if this problem could be solved. A strategy would be to leave the group but, again due to the importance of social support, this strategy would often be a last resort. In many situations, the fitness benefits of staying in a group with an exploitative leader would outweigh the benefits of voluntary ostracism. Another more viable strategy, which we argue is crucial for the understanding of the psychology of procedural fairness, would be to seek to replace the leader with a leader with a higher WTR or, through the threat of replacement, up-regulate the 
current leader's WTR. ${ }^{7}$ Essentially, these outcomes entail a political renegotiation of the hierarchy within the collective.

As argued above, the crucial tool for hierarchy negotiations is the formation and mobilization of alliances. While an exploitative group leader should easily be able to ignore a single individual's efforts to counter-act exploitation such reactions should be harder to bypass when supported by a coalition of followers. Anthropological studies have shown how followers engage in political alliances of moral communities to counteract dominant behavior through levelling mechanisms of gossip, criticism, ridicule, disobedience and, in the last instance, banishment or assassination of out-of-line leaders (Boehm 1993; 1999). Moreover, computer simulations suggest that such mobilization of coalitions against exploitative leaders could be adaptive under ancestral conditions (Gavrilets et al. 2008; Gavrilets 2012).

We argue that the transition from the problem of identifying leaders with a low WTR towards the self to the problem of mobilizing others to deal with that problem has shaped the psychology of procedural fairness in important ways. It constitutes a key, separate evolved function of procedural fairness. In particular, we argue that it is impossible to understand the moralistic nature of attention to procedural features without understanding the need for mobilization.

Let us consider a follower, named A, that suffers costs because a leader, $\mathrm{X}$, has a low WTR towards A. Only under two conditions would it make adaptive sense for a set of other

\footnotetext{
${ }^{7}$ As described in footnote 5 , it is possible to distinguish between intrinsic and monitored WTRs. In principle, it is adaptive for a follower to seek to increase both WTRs of a leader. However, because intrinsic WTRs are set by factors related to kinship and deep friendship, it is difficult to recalibrate these to a significant extent. Hence, the bargaining strategies we describe here refer to attempts to up-regulate monitored WTRs. In relation to intrinsic WTRs, the task of a follower is instead to actively disengage the intrinsic WTRs of a leader from the leaders' decision-making process. That is, to ensure that the private affiliations of leaders do not shape their decisions. This will be the case for decision-making processes that conform to procedural fairness criteria. In fact, within the conceptual framework of WTRs, one can define a leader's decision as impartial to the extent it is uncorrelated with the leader's WTRs. It should also be noted that impartiality is often not in itself an adaptive target for the individual follower. Each follower holds an interest in increasing the WTRs of the leader towards the self to the largest extent possible. However, since upregulating a leader's WTR requires coalitional coordination, the only arrangement equally powerful followers can coordinate on is to opt for equal treatment of individuals (i.e. disengage intrinsic WTRs all together and upregulate monitored WTRs to the same average for all followers).
} 
followers - B, C and D-to aid A against $\mathrm{X}$. The first condition is if $\mathrm{B}, \mathrm{C}$ and $\mathrm{D}$ had a high WTR toward A; that is, if they valued A's welfare because of A's value as a reciprocation partner or kin. In such a case, the costs imposed on A would yield indirect costs on B, C and D and, hence, X's exploitation would constitute a shared problem. Under ancestral conditions with dense social networks, this condition might indeed have occurred with some frequency. At the same time, it should be noted that only a fraction of the costs imposed on A are experienced by B, C and D (specifically, the costs imposed on A weighted by how much they each value A's welfare) and, hence, $\mathrm{B}, \mathrm{C}$ and $\mathrm{D}$ will be less motivated than ideally seen from the perspective of $\mathrm{A}$. The second condition, however, would provide stronger motivations to aid A. If X did not just hold low WTRs towards A but also low WTRs towards B, C and D, these other followers should be as motivated to aid A against $\mathrm{X}$ as A would be to get $\mathrm{X}$ away from the top position. From a mobilization perspective, if A detects that X holds a low WTR, it is therefore in the interest of A to broadcast information that can convince other followers that they themselves are in the same situation: facing an exploitative leader. Because of this, the selection pressures that have structured our psychology of procedural fairness should have implemented a motivation to scan for those precise procedural features that would signify that not only the self but also others are being exploited and, upon detection, broadcast these widely.

This, we argue, has structured the content of intuitions of procedural fairness. Intuitions of procedural fairness tag processes that lead to negative outcomes for the self as immoral and unfair to the extent these lack impartiality and that not all relevant parties are involved in a balanced way and are able to voice their opinion. Attending to and moralizing these particular features is, seen from the perspective of an individual follower, crucial because they signify that the leader holds low WTRs towards a larger segment of the collective and helps that individual mobilize others on his behalf. In this way, the psychology 
of procedural fairness directs attention towards the specific information that will make it most likely that others will come to the aid of the individual.

Intuitions about procedural fairness serve as an effective coordination device for group members with coinciding interests to mobilize their efforts and form political coalitions with the power to counteract exploitation. By insisting that everyone gets a voice in authoritative decision-making and that the group leader has no personal interest in the decision (along with the other criteria displayed in Figure 1), followers hold an effective means for keeping exploitative leaders in check. Specifically, by enforcing procedural fairness criteria in authoritative decision-making, each follower can make sure that they are not receiving disproportionally worse treatment than others. Of course, for each individual follower it would be better to receive disproportionally better treatment but, given the constraints emerging from the need for coalitional support, impartiality provides a feasible, second-best option.

These observations do not imply that a follower does not react negatively to negative outcomes that stems from processes that live up to procedural fairness criteria (people also care about outcome favorability and distributive justice, see e.g. Törnblom \& Vermunt 2007). The reaction, however, only becomes moralistic when others can be expected to mobilize on behalf of the follower. As argued forcefully by DeScioli and Kurzban (2013), morality is specifically designed for coordinating collective responses and our moral psychology has a suite of design features that enable it to fulfill this function (Petersen 2013). These include that (1) the detection of behavior that violates moral rules elicit feelings of moral outrage (Tetlock 2003); (2) outrage motivates the imposition of costs (social and/or physical) on those committing them and, hence, serve to incentivize moral behavior (Jensen \& Petersen 2011); (3) outrage also creates a motivation to spread information about the perpetrator and the offense (e.g., through gossip); hence, helping spread the feeling of outrage; (4) the 
motivation to spread information is sustained by a belief that moral intuitions are universally shared and, hence, that others will respond in kind (Turiel 1983); (5) the content of moral intuitions and rules are explained with reference to a collective good that makes them (appear) in the interest of the majority and, hence, further facilitating the spread of outrage. Intuitions of procedural fairness match this template.

We emphasize that attention to procedural fairness is strategic in nature. It evolved to increase fitness of the individual and not to help the group at large. As described in detail in the preceding section, advocating for procedural fairness and morally condemning exploitative group leaders is exercised by group members who themselves are subject to exploitation, while those unaffected or benefitting from exploitative or nepotistic leaders should be less inclined to condemn or counteract such behavior. These findings demonstrate that people, at least in part, broadcast notions of procedural fairness strategically when they have an incentive to upregulate WTRs of leaders in group decision making. Put differently, there is an instrumental 'brake' on moral outrage against leaders breaking procedural fairness criteria in situations where such outrage would not serve to increase the fitness of the individual. At the same time, it should be noted that the only rules that everybody can agree upon are rules that provide people with equal status in the decision-making process. If power is equally dispersed in a group, the de facto outcome of everybody's strategic moralization (i.e., trying to mobilize others for the rules that make the self best off) will therefore be a rule that makes everybody equal. Something that looks as if it was implemented for the benefit of everybody can in this way emerge from the collective coordination of self-interest. In sum, intuitions about procedural fairness serve as a coordination device for group members to form political coalitions and impose criteria in group decision making that serve to upregulate WTRs of leaders towards the self. 


\section{Evolutionary Mismatches: The Evolved Functions of Procedural Fairness and Modern}

\section{Politics}

The ultimate explanation of procedural fairness, we have argued, relates to the politics of ancestral groups. Our psychology of procedural fairness is designed to solve the complex and multi-layered adaptive problems that arise when political power is negotiated.

Specifically, intuitions of procedural fairness help us to safely delegate political power to others in return for services by providing a cognitive and motivational machinery that constantly monitors whether these leaders continue to be favorably disposed towards us and orchestrate collective outrage against those who are not.

The empirical evidence that we have reviewed above has mainly been conducted in settings that are not political in the everyday sense of this term: small-scale, interpersonal settings such as in legal, managerial and educational settings. At the same time, these smaller social settings are in many ways more parallel to the political settings of our ancestors than are mass politics settings. Humans have lived in small-scale, simple hunter-gatherer societies of no more than 50-150 individuals for nearly 2.5 million years. State-liked societies with potential for mass politics only emerged extremely recently in evolutionary terms (Diamond 1999; Wade 2007).

This is important because evolution is a slow and protracted process. Psychological mechanisms shaped by natural selection—-such as those underlying notions of procedural fairness - should therefore be adapted to function within the ancestral, small-scale environment in which they evolved rather than the present environments (Tooby \& Cosmides 1990). A consequence is that differences between ancestral and modern environments (sometimes referred to as mismatches) imply that the operations of psychological mechanisms might not always be fitness-enhancing under modern conditions (Hagen \& Hammerstein 2006). One prominent example concerns the innate human fear of spiders and 
snakes, which still, although not posing a significant threat in a modern context, is perceived as more dangerous than contemporary dangers like electric outlets or guns (Ohman \& Mineka 2001). Such a mismatch also manifests itself in modern political attitude formation (Petersen \& Aarøe 2012) and in evaluations of modern-day political leaders (Van Vugt et al. 2008).

In this final section, we review evidence that suggest that a mismatch between ancestral and modern conditions is also shaping the way intuitions about procedural fairness enter judgments and behaviors in the context of modern politics. As anthropologists Erdal \& Whiten $(1996,158)$ also note, ancestral psychological mechanisms designed to counteract exploitative group leaders "need not in principle lead to behavior which is functionally effective" in a modern context since the "correlation between the proximate cause of the behavior and the genetic function of the behavior may be broken in a radically different environment". Specifically, we suggest that a number of cues that draw attention away from violations of procedural fairness in small-scale settings are lacking or are less vivid in the context of large-scale politics. In other words, for reasons provided below we should expect there to be no instrumental 'brake' on moral outrage following a breach of procedural fairness criteria in a political context. Accordingly, modern politics come to be shaped by procedural fairness even more strongly than many other contexts.

Evidence from political science indicates that notions of procedural fairness also play an important role in politics today. Recent public opinion research has demonstrated that notions of procedural fairness influence trust in a variety of modern political institutionssuch as government, national courts, administrative units, political parties and political representatives - such that institutions that conform to our intuitions of procedural fairness receive more trust (Tyler 1994; Grimes 2006; Ramirez 2008; Bøggild 2014). Political policies that are passed after processes that conform to our intuitions of procedural fairness are also supported to a higher extent (Bøggild, 2014). Furthermore, a number of studies on 
political communication suggest that media audiences desire information about the strategic and self-interested motivations of politicians and that news editors happily provide such coverage. For example, a recent study has demonstrated a "news-selection bias" in which people seek strategic news covering self-interested motivations and actions of politicians over standard issue-related coverage of politics (Trussler \& Soroka 2014). At the same time, such coverage is easy and inexpensive to produce and is therefore willingly supplied by political analysts and news editors (Patterson 1994; Farnsworth \& Lichter 2010). In addition, negative campaigns from politicians vigorously question the moral quality and dispositional tendencies of their political opponents (Lau \& Rovner 2009). In short, information about exploitative and self-serving tendencies of modern political leaders is both high in supply and demand.

Procedural fairness is also of obvious importance in small-scale social settings but, as reviewed in the preceding sections, it is a standard finding that individuals pay less attention to procedural information when the relevant decisions do not impose costs on these individuals. According to three recent studies, this instrumental "brake" on procedural fairness is not operating in mass politics. Two studies have considered whether attention to procedural information interacts with the favorability of the outcome in a political context. One study (Bøggild 2014) investigated the effects of impartiality on trust in political decision makers and support for public policies. More specifically, the study showed through three survey experiments that trust in a political decision maker and support for its political decision was in part a function of whether or not the decision maker had a personal, votemaximizing and ultimately reelection motive in introducing the decision. However, contrary to the extensive literature in social psychology, these effects were not moderated by outcome favorability. Across three different studies with different operationalizations of outcome favorability the effects of impartial decision-making were constant and substantial, 
independently of whether outcomes were favorable to the individual or not. A second study (Kumlin 2004) demonstrated a significant correlation between citizens' perceived voice opportunities in political decision-making processes and general trust in politicians. This effect, however, did not differ across individuals expressing different levels of satisfaction with the services they received from the state. This study concluded that in a political context there is "very little support for the hypothesis that the impact of voice grows with service dissatisfaction" (Kumlin 2004, 263). A third study considered whether attention to procedural information interacted with whether the individual was influenced by an outcome. Grimes (2005) used panel data to show that trust in a political, administrative unit and support for its political decision depended on two procedural criteria in terms of perceived voice opportunities and the decision maker's willingness to justify its decision publicly. However, this study found little support for the expectation that these effects were larger among those affected by the decision. The effects of public justification on both trust in the administrative unit and support for its decision were constant across those affected and unaffected by the decision. The effect of voice opportunities on trust in the administrative unit was also constant across these segments, while there was a tendency for the effect of voice opportunities on support for the political decision to be marginally larger among those affected by the decision. That is, out of four interaction terms only one was marginally significant, which testifies to a limited, if any, moderating effect of outcome dependence in a large-scale political setting. In the context of mass politics, people assign weight to procedural fairness concerns independently of whether they were affected by the political decision or not (Grimes 2005, 131).

The finding that personal self-interest is less effective in regulating psychological responses in mass politics than in other contexts is consistent with both classical research in political science (Sears \& Funk 1991) and research from an evolutionary perspective 
(Petersen \& Aarøe 2012). Given the contextual differences between modern politics and ancestral environments, this attenuated role of self-interest is not unexpected. Multiple differences add to this outcome: First, the novel and technical nature of many political issues makes it difficult for our psychology to compute the costs and benefits of various policies for our welfare on the basis of evolutionarily recurrent information. Second, the length of the causal link between a policy decision and its personal consequences implies that many people primarily ascribe negative outcomes to personal rather than political choices (see Feldman 1982). Third, our evolved decision-making psychology — designed to operate on the basis of the vivid, social cues that inhere in face-to-face interaction-have less clear cues available in the abstract context of mass politics: most people won't know and will never meet most of those affected by policy decisions (Petersen \& Aarøe 2013). All these processes add up and make people perceive politics as abstract, remote and disconnected from their everyday lives (Lippmann 1922; Schumpeter 1943; Lane 1962). Because of this, politics can easily be psychologically represented as an arena for cheap signals of one's moral commitments; an arena where one can send a signal without paying the costs of forfeiting one's self-interest. Rather than self-interest, symbols such as those related to procedural fairness become a key factor when people form political opinions (Herek 1986; Sears \& Funk 1991; Inglehart 2008). In modern politics notions of procedural fairness are important. In fact, because of evolutionarily mismatches between ancestral and modern environments these notions potentially gain more importance today than ancestrally. Because of the difficulties in connecting self-interest and politics, there is no instrumental "brake" on moral outrage against group leaders in modern, mass contexts. Aided by mass and social media, moralization can "run free" without a direct connection to the instrumental, fitness-related goals that these moral intuitions originally evolved to fulfill. In mass politics, as suggested by the recent empirical studies, procedural fairness intuitions might not merely manifest 
themselves strategically in situations where they serve a clear fitness-related purpose but affect opinions in a more universal and unconditional manner. Thus, in a political context in particular "the means is the end" (Hibbing \& Theiss-Morse 2001, 243) and constitute important "procedural goods" to citizens of democratic societies (Lane 1988).

\section{Conclusion}

In this chapter, we argued that intuitions of procedural fairness reflect a psychological machinery that evolved by natural selection to help our ancestors solve adaptive problems related to politics. This evolutionary perspective on procedural fairness contributes to the existing literature in three important ways.

First, it offers new theoretical insights by arguing that notions of procedural fairness serve both a 1) a diagnostic function in evaluating WTRs and exploitative tendencies of group leaders and 2) a bargaining function in terms of mobilizing support against exploitative leaders and bargain for better outcomes. As stressed throughout the chapter, an evolutionary perspective does not discredit existing models offered by social psychologists but rather allows for a synthesis between these more proximate models. From an evolutionary perspective, information on procedural fairness does serve as a means for the individual to evaluate its relationship with the group authority and status within the group (in line with the relational model of authority). However, attention to these cues does not ultimately stem from a need to construct a social identity but rather serves to reduce uncertainties as to whether an authority can be trusted or will exploit followers for self-interested reasons (in line with fairness heuristic theory). Moreover, notions of procedural fairness serve a direct instrumental purpose as an effective means for bargaining for better outcomes (in line with the instrumental model). Hence, these theoretical models have provided and will continue to 
provide useful insights on the effects and psychological function of procedural fairness. However, an evolutionary perspective, we argue, provides an important organizing principle and metatheoretical paradigm for synthesizing existing theoretical models and empirical findings and for further hypothesis generation. The existing literature has mainly (but not exclusively) focused on procedural fairness as a diagnostic tool and future work could benefit from considering how notions of procedural fairness are used as a strategic bargaining tool and as a coordination device for followers with coinciding interests to engage in moral communities and enforce moral constraints on the discretionary power of group leaders.

Second, an evolutionary perspective offers potential conceptual advancements to the procedural fairness literature. In spite of the extensive empirical support for the effects of procedural fairness, conceptual work in this literature remains "in its early stages" (Cloutier \& Vilhuber 2008, p. 714). The criteria displayed in Figure 1 are most often referred back to Leventhal (1980), who provides no account for how or from where these criteria are deduced. As a result, although most would probably concur with the fairness of the criteria displayed in Figure 1, we are still left unaware of what "fair" actually means. An evolutionary perspective, however, provides an ultimate account of procedural fairness and hence allows for a systematic deduction of relevant procedural criteria or principles. An evolutionary perspective entails a functionalist approach to procedural fairness, analyzing the concept from the starting point of the fundamental need or problem it was designed to accommodate. Hence, any non-outcome information related to authoritative decision-making that would somehow serve as a reliable cue for WTRs of leaders should be relevant components in procedural fairness evaluations. Arguably, all of the existing procedural criteria displayed in Figure 1 should fit under this simple conceptualization. For example, nature should have selected against individuals who did not respond with moral outrage and anger when group leaders refused them a say in group decisions (voice) or had vested interests in the decisions 
introduced (impartiality) (for similar naturalistic conceptualizations of distributive fairness see Krebs 2008; Binmore 2011).

Third, an evolutionary perspective provides a possible account of recent divergent findings on procedural fairness in social psychological and political settings and stresses important differences between social and political cognition more generally. In a political context - in contrast to small-scale, inter-personal settings such as in the courtroom or in the workplace - people often fail to see the connection between their opinions or behaviors and their immediate self-interest. Hence, in a political context moralization and fairness intuitions "run free" and become detached from the instrumental function they originally evolved to fulfill. Similar findings have been demonstrated on other political issues as well such as on public opinion towards immigration. Specifically, scholars have demonstrated that the evolved psychological system of disgust, which originally evolved to help the individual avoid contact with pathogens, is an important factor in explaining attitudes towards immigration. Even though catching an infection from interacting with individuals belonging to a different ethnic group in a modern-day context would be extremely low, priming people with disgusting images or smells still drives up anti-immigration attitudes significantly (Faulkner et al. 2004). Hence, evolved disease-avoidance mechanisms play an important role in public opinion formation although they may not serve the survival-based function they originally evolved to fulfill. Future work should consider more systematically how evolved cognitive systems might "run free" and become detached from their survival based function in a large-scale modern political context.

In closing, an evolutionary perspective suggests that we should also be cautious about the potential downsides of the effects of procedural fairness. Humans might not only be equipped with notions of procedural fairness in order to defend against exploitation but also with counter-adaptations designed to circumvent such defenses in others (Whiten \& Byrne 
1997; Buss \& Duntley 2008). For example, leaders might attempt to appear procedurally fair (e.g. by allowing group members voice) to avoid being held accountable for risky or poor decision-making (MacCoun 2005; DeScioli \& Bokemper 2014). This implies that procedural fairness could also be applied in a manipulative sense to conceal incompetence or selfserving dispositions in a leadership role. 


\section{References}

Aalberg, Toril, Jesper Strömbäck, and Claes H. de Vreese. 2011. "The Framing of Politics as Strategy and Game: A Review of Concepts, Operationalizations and Key Findings.” Journalism 13 (2): 1464884911427799. doi:10.1177/1464884911427799.

Beijersbergen, Karin A, Anja J E Dirkzwager, Veroni I Eichelsheim, Peter H van der Laan, and Paul Nieuwbeerta. 2014. "Procedural Justice and Prisoners' Mental Health Problems: A Longitudinal Study." Criminal Behaviour and Mental Health: CBMH 24 (2): 100-112. doi:10.1002/cbm.1881.

Beugré, Constant D. 2009. "Exploring the Neural Basis of Fairness: A Model of NeuroOrganizational Justice.” Organizational Behavior and Human Decision Processes 110 (2): 129-39.

Binmore, Ken. 2011. Natural Justice. Oxford: Oxford University Press.

Blader, Steven L, and Tom R Tyler. 2003. “A Four-Component Model of Procedural Justice: Defining the Meaning of a 'Fair' Process." Personality \& Social Psychology Bulletin 29 (6): 747-58. doi:10.1177/0146167203029006007.

Boehm, Christopher. 1993. "Egalitarian Behavior and Reverse Dominance Hierarchy." Current Anthropology 34 (3): 227. doi:10.1086/204166.

- 1999. Hierarchy in the Forest: The Evolution of Egalitarian Behavior. Harvard University Press.

Bøggild, T. 2014. "Do the Means Justify the Ends? Procedural Fairness, Politicians' Reelection Motives, and Support for Public Policy." Paper Presented at the Annual Meeting of the Midwest Political Science Association, Chicago, 2014.

Boyd, Robert, and Peter J. Richerson. 1988. Culture and the Evolutionary Process. Chicago: University Of Chicago Press. 
Brockner, J, and B M Wiesenfeld. 1996. “An Integrative Framework for Explaining Reactions to Decisions: Interactive Effects of Outcomes and Procedures.” Psychological Bulletin 120 (2): 189-208.

Buss, David M., and Joshua D. Duntley. 2008. “Adaptations for Exploitation.” Group Dynamics: Theory, Research, and Practice 12 (1): 53-62. doi:10.1037/10892699.12.1.53.

Cappella, Joseph N., and Kathleen Hall Jamieson. 1996. "News Frames, Political Cynicism, and Media Cynicism." The ANNALS of the American Academy of Political and Social Science 546 (1): 71-84. doi:10.1177/0002716296546001007.

Charness, Gary, and David Levine. 2007. "Intention and Stochastic Outcomes: An Experimental Study.” Economic Journal 117 (522): 1051-72. doi:10.2139/ssrn.437870.

Cloutier, Julie, and Lars Vilhuber. 2008. "Procedural Justice Criteria in Salary Determination.” Journal of Managerial Psychology 23 (6): 713-40. doi:10.1108/02683940810894765.

Colquitt, Jason A. 2001. "On the Dimensionality of Organizational Justice: A Construct Validation of a Measure.” Journal of Applied Psychology 86 (3): 386-400. doi:10.1037/0021-9010.86.3.386.

Cosmides, L, and J Tooby. 1997. "Dissecting the Computational Architecture of Social Inference Mechanisms." In Characterizing Human Psychological Adaptations (Ciba Foundation Symposium \#208), Wiley, 132-56. Chichester.

Cremer, David De, and Daan van Knippenberg. 2003. "Cooperation with Leaders in Social Dilemmas: On the Effects of Procedural Fairness and Outcome Favorability in Structural Cooperation." Organizational Behavior and Human Decision Processes 91 (1): 1-11. doi:10.1016/S0749-5978(02)00539-3. 
Daileyl, Robert C., and Delaney J. Kirk. 1992. "Distributive and Procedural Justice as Antecedents of Job Dissatisfaction and Intent to Turnover." Human Relations 45 (3): 305-17. doi:10.1177/001872679204500306.

De Cremer, David, Barbara van Knippenberg, Daan van Knippenberg, Danny Mullenders, and Florence Stinglhamber. 2005. "Rewarding Leadership and Fair Procedures as Determinants of Self-Esteem.” The Journal of Applied Psychology 90 (1): 3-12. doi:10.1037/0021-9010.90.1.3.

Delton, Andrew W., Leda Cosmides, Marvin Guemo, Theresa E. Robertson, and John Tooby. 2012. "The Psychosemantics of Free Riding: Dissecting the Architecture of a Moral Concept.” Journal of Personality and Social Psychology 102 (6): 1252-70. doi:10.1037/a0027026.

DeScioli, Peter, and Scott Bokemper. 2014. "Voting as a Counter-Strategy in the Blame Game.” Psychological Inquiry 25 (2): 206-14. doi:10.1080/1047840X.2014.901130.

DeScioli, Peter, and Robert Kurzban. 2013. "A Solution to the Mysteries of Morality." Psychological Bulletin 139 (2): 477-96. doi:10.1037/a0029065.

De Waal, Frans B. 2007. Chimpanzee Politics: Power and Sex Among Apes. Baltimore: JHU Press.

De Waal, Frans B. 1997. Good Natured The Origins of Right and Wrong in Humans and Other Animals. Cambridge: Harvard University Press.

Diamond, Jared M. 1999. Guns, Germs and Steel: The Fates of Human Societies. New York: Norton.

Dubreuil, Benoit. 2011. Human Evolution and the Origins of Hierarchies: The State of Nature. New York: Cambridge University Press.

Dulebohn, James H. 2009. “The Biological Bases of Unfairness : Neuroimaging Evidence for the Distinctiveness of Procedural and Distributive Justice." 
Easton, D. 1953. An Inquiry into the State of Political Sciences. New York: Knopf.

Erdal, David, and Andrew Whiten. 1996. "Egalitarian and Machiavellian Intelligence in Human Evolution.” In Modelling the Human Mind, Mellars, Paul \& Gibson, Kathleen. Cambridge: McDonal institute Monographies.

Falk, Armin, Ernst Fehr, and Urs Fischbacher. 2008. “Testing Theories of fairnessIntentions Matter." Games and Economic Behavior 62 (1): 287-303. doi:10.1016/j.geb.2007.06.001.

Farnsworth, Stephen J., and Robert S. Lichter. 2010. The Nightly News Nightmare: Media Coverage of U.S. Presidential Elections, 1988-2008. Third Edition edition. Lanham, Md: Rowman \& Littlefield Publishers.

Faulkner, Jason, Mark Schaller, Justin H. Park, and Lesley A. Duncan. 2004. "Evolved Disease-Avoidance Mechanisms and Contemporary Xenophobic Attitudes.” Group Processes \& Intergroup Relations 7 (4): 333-53. doi:10.1177/1368430204046142.

Feldman, Stanley. 1982. "Economic Self-Interest and Political Behavior." American Journal of Political Science 26 (3): 446-66. doi:10.2307/2110937.

Foley, Robert. 1995. "The Adaptive Legacy of Human Evolution: A Search for the Environment of Evolutionary Adaptedness.” Evolutionary Anthropology: Issues, News, and Reviews 4 (6): 194-203. doi:10.1002/evan.1360040603.

Folger, Robert, and Mary A. Konovsky. 1989. "Effects of Procedural and Distributive Justice on Reactions to Pay Raise Decisions." The Academy of Management Journal 32 (1): $115-30$.

Fry, P. S., and V. K. Corfield. 1983. “Children\&\#039;s Judgments of Authority Figures with Respect to Outcome and Procedural Fairness." The Journal of Genetic Psychology 143 (2): 241-50. doi:10.1080/00221325.1983.10533557. 
Furer-Haimendorf, Christoph Von. 1967. Morals and Merit. A Study in Values and Social Controls in South Asian Societies. 1St Edition edition. University Of Chicago Press. Gavrilets, Sergey. 2012. "On the Evolutionary Origins of the Egalitarian Syndrome." Proceedings of the National Academy of Sciences, August, 201201718. doi:10.1073/pnas.1201718109.

Gavrilets, Sergey, Edgar A. Duenez-Guzman, and Michael D. Vose. 2008. "Dynamics of Alliance Formation and the Egalitarian Revolution.” PLoS ONE 3 (10): e3293. doi:10.1371/journal.pone.0003293.

Giacobbe-Miller, Jane K., Daniel J. Miller, and Vladimir I. Victorov. 1998. “A Comparison of Russian and U.s. Pay Allocation Decisions, Distributive Justice Judgments, and Productivity Under Different Payment Conditions.” Personnel Psychology 51 (1): 137-63. doi:10.1111/j.1744-6570.1998.tb00719.x.

Gold, Laura J., John M. Darley, James L. Hilton, and Mark P. Zanna. 1984. “Children’s Perceptions of Procedural Justice.” Child Development 55 (5): 1752-59. doi: $10.2307 / 1129922$.

Gonzalez, C.M, and T. R. Tyler. 2007. "Why Do People Care about Procedural Fairness? The Importance of Membership Monitoring." In Distributive and Procedural Justice, 2007th ed., 91-111. Abingdon, Oxon: Ashgate.

Grimes, Marcia. 2005. “Democracy’s Infrastructure: The Role of Procedural Fairness in Fostering Consent." Doctoral thesis. http://gup.ub.gu.se/publication/31280democracys-infrastructure-the-role-of-procedural-fairness-in-fostering-consent. . 2006. "Organizing Consent: The Role of Procedural Fairness in Political Trust and Compliance.” European Journal of Political Research 45 (2): 285-315. doi:10.1111/j.1475-6765.2006.00299.x. 
Hagen, Edward H, and Peter Hammerstein. 2006. "Game Theory and Human Evolution: A Critique of Some Recent Interpretations of Experimental Games.” Theoretical Population Biology 69 (3): 339-48. doi:10.1016/j.tpb.2005.09.005.

Haidt, Jonathan. 2013. The Righteous Mind: Why Good People Are Divided by Politics and Religion. New York: Vintage Books.

Ham, J., and K. van den Bos. 2008. "Not Fair for Me! The Influence of Personal Relevance on Social Justice Inferences.” Journal of Experimental Social Psychology 44: 699705.

Henrich, Joseph, and Francisco J Gil-White. 2001. "The Evolution of Prestige: Freely Conferred Deference as a Mechanism for Enhancing the Benefits of Cultural Transmission.” Evolution and Human Behavior 22 (3): 165-96. doi:10.1016/S1090$5138(00) 00071-4$.

Herek, Gregory M. 1986. “The Instrumentality of Attitudes: Toward a Neofunctional Theory.” Journal of Social Issues 42 (2): 99-114. doi:10.1111/j.15404560.1986.tb00227.x.

Hibbing, John R., and John R. Alford. 2004. “Accepting Authoritative Decisions: Humans as Wary Cooperators." American Journal of Political Science 48 (1): 62-76. doi:10.1111/j.0092-5853.2004.00056.x.

Hibbing, John R., and Elizabeth Theiss-Morse. 2001. What Is It about Government That Americans Dislike?. Cambridge University Press.

_. 2008. "Voice, Validation, and Legitimacy." In Cooperation: The Political Psychology of Effective Human Interaction, 123-42. Blackwell: Malden, MA.

Hicks, Anthony J., and Jeanette A. Lawrence. 1993. “Children's Criteria for Procedural Justice: Developing a Young People’s Procedural Justice Scale.” Social Justice Research 6 (2): 163-82. doi:10.1007/BF01048475. 
Hill, Sarah E., and David M. Buss. 2006. “The Evolution of Self-Esteem.” In Self-Esteem: Issues and Answers, M. H. Kernis. New York: Psychology Press.

Inglehart, Ronald F. 2008. "Changing Values among Western Publics from 1970 to 2006." West European Politics 31 (1-2): 130-46. doi:10.1080/01402380701834747.

Jensen, N, and M Petersen. 2011. "To Defer or to Stand up? How Offender Formidability Affects Third Party Moral Outrage.” Evolutionary Psychology 9 (1): 118-36.

Kenrick, Douglas T, Norman P Li, and Jonathan Butner. 2003. “Dynamical Evolutionary Psychology: Individual Decision Rules and Emergent Social Norms.” Psychological Review 110 (1): 3-28.

Khatri, Naresh, Chong Tze Fern, and Pawan Budhwar. 2001. "Explaining Employee Turnover in an Asian Context." Human Resource Management Journal 11 (1): 54-74. doi:10.1111/j.1748-8583.2001.tb00032.x.

Koper, Gerda, Daan Van Knippenberg, Francien Bouhuijs, Riel Vermunt, and Henk Wilke. 1993. "Procedural Fairness and Self-Esteem.” European Journal of Social Psychology 23 (3): 313-25. doi:10.1002/ejsp.2420230307.

Krebs, D. L. 2008. “The Evolution of a Sense of Justice.” In Evolutionary Forensic, Duntley, J \& T. K. Shackelford. Oxford University Press.

Krislov, Samuel. 1991. "Why Do People Obey the Law?” Journal of Public Administration Research and Theory 1 (2): 235-39.

Kumlin, Staffan. 2004. The Personal and the Political. Edited by Bo Rothstein and Sven Steinmo. Basingstoke: Palgrave Macmillan.

Lane, Robert E. 1988. "Procedural Goods in a Democracy: How One Is Treated versus What One Gets.” Social Justice Research 2 (3): 177-92. doi:10.1007/BF01054555.

Lane, Robert Edwards. 1962. Political Ideology: Why the American Common Man Believes What He Does. Free Press of Glencoe. 
Lasswell, H. 1950. Politics: Who Gets What, When, How. New York: P. Smith.

Lau, R, and I Rovner. 2009. "Negative Campaigning.” Annual Review of Political Science 12: $285-306$.

Laustsen, Lasse, and Michael Bang Petersen. 2015. "Does a Competent Leader Make a Good Friend? Conflict, Ideology and the Psychologies of Friendship and Followership.” Evolution and Human Behavior Forthcoming. doi:10.1016/j.evolhumbehav.2015.01.001.

Lavelle, James J., Joel Brockner, Mary A. Konovsky, Kenneth H. Price, Amy B. Henley, Aakash Taneja, and Vishnu Vinekar. 2009. “Commitment, Procedural Fairness, and Organizational Citizenship Behavior: A Multifoci Analysis.” Journal of Organizational Behavior 30 (3): 337-57. doi:10.1002/job.518.

Leary, M. R., and R. F. Baumeister. 2000. “The Nature and Function of Self-Esteem: Sociometer Theory." In Advances in Experimental Social Psychology, M Zanna. San Diego: Academic Press.

Leary, M. R., and D. L. Downs. 1995. "Interpersonal Functions of the Self-Esteem Motive: The Self-Esteem System as a Sociometer.” In Efficacy, Agency, and Self-Esteem. New York: Plenum.

Leung, Kwok, Kwok-Kit Tong, and E. Allan. 2007. "Realpolitik versus Fair Process: Moderating Effects of Group Identification on Acceptance of Political Decisions.” Journal of Personality and Social Psychology 92 (3): 476-89. doi:10.1037/00223514.92.3.476.

Leventhal, G. S. 1980. "What Should Be Done with Equity Theory?” In Social Exchange: Advances in Theory and Research. New York: Plenum. 
Lind, E. A., Ruth Kanfer, and P. Christopher. 1990. "Voice, Control, and Procedural Justice: Instrumental and Noninstrumental Concerns in Fairness Judgments.” Journal of Personality and Social Psychology 59 (5): 952-59. doi:10.1037/0022-3514.59.5.952. Lind, E. Allan, and T. R. Tyler. 1988. The Social Psychology of Procedural Justice. Springer. Lippmann, Walter. 1922. Public Opinion. Harcourt, Brace.

MacCoun, Robert J. 2005. "VOICE, CONTROL, AND BELONGING: The Double-Edged Sword of Procedural Fairness.” Annual Review of Law and Social Science 1 (1): 171201. doi:10.1146/annurev.lawsocsci.1.041604.115958.

Meggitt, Mervyn. 1978. Blood Is Their Argument: Warfare Among the Mae Enga Tribesmen of the New Guinea Highlands. 1 edition. McGraw-Hill Humanities/Social Sciences/Languages.

Ohman, A., and S. Mineka. 2001. "Fears, Phobias, and Preparedness: Toward an Evolved Module of Fear and Fear Learning." Psychological Review 108 (3): 483-522.

Ong, Qiyan, Yohanes E. Riyanto, and Steven M. Sheffrin. 2012. "How Does Voice Matter? Evidence from the Ultimatum Game.” Experimental Economics 15 (4): 604-21.

Patterson, Thomas E. 1994. Out of Order. New York: Vintage Books.

Petersen, M. 2015. “Evolutionary Political Psychology.” In Handbook of Evolutionanry Psychology, Buss, D. Hoboken: John Wiley \& Sons Ltd.

Petersen, Michael Bang. 2013. "Moralization as Protection against Exploitation: Do Individuals without Allies Moralize More?" Evolution and Human Behavior 34 (2): 78-85. doi:10.1016/j.evolhumbehav.2012.09.006.

Petersen, Michael Bang, and Lene Aarøe. 2012. "Is the Political Animal Politically Ignorant? Applying Evolutionary Psychology to the Study of Political Attitudes.” Evolutionary Psychology: An International Journal of Evolutionary Approaches to Psychology and Behavior 10 (5): 802-17. 
Petersen, Michael Bang, and Lene AARøe. 2013. "Politics in the Mind's Eye: Imagination as a Link between Social and Political Cognition." American Political Science Review 107 (02): 275-93. doi:10.1017/S0003055413000026.

Petersen, Michael Bang, Aaron Sell, John Tooby, and Leda Cosmides. 2012. "To Punish or Repair? Evolutionary Psychology and Lay Intuitions about Modern Criminal Justice.” Evolution and Human Behavior 33 (6): 682-95. doi:10.1016/j.evolhumbehav.2012.05.003.

Petersen, M, A Sell, J Tooby, and L Cosmides. 2010. "Evolutionary Psychology and Criminal Justice: A Recalibrational Theory of Punishment and Reconciliation.” In Human Morality \& Sociality: Evolutionary \& Comparative Perspectives, HøeghOlesen, H., 72-131. New York: Palgrave Macmillan.

Pillai, Rajnandini, Chester A. Schriesheim, and Eric S. Williams. 1999. "Fairness Perceptions and Trust as Mediators for Transformational and Transactional Leadership: A TwoSample Study.” Journal of Management 25 (6): 897-933. doi:10.1177/014920639902500606.

Pillai, Rajnandini, Eric S. Williams, and J. Justin Tan. 2001. “ARE THE SCALES TIPPED IN FAVOR OF PROCEDURAL OR DISTRIBUTIVE JUSTICE? AN INVESTIGATION OF THE U.S., INDIA, GERMANY, AND HONG KONG (CHINA)." International Journal of Conflict Management 12 (4): 312-32. doi:10.1108/eb022861.

Platow, Michael J., Rachael A. Eggins, Rachana Chattopadhyay, Greg Brewer, Lisa Hardwick, Laurin Milsom, Jacinta Brocklebank, et al. 2013. “Two Experimental Tests of Relational Models of Procedural Justice: Non-Instrumental Voice and Authority Group Membership.” The British Journal of Social Psychology / the British Psychological Society 52 (2): 361-76. doi:10.1111/j.2044-8309.2011.02083.x. 
Popkin, Samuel L. 1991. The Reasoning Voter: Communication and Persuasion in Presidential Campaigns. University of Chicago Press.

Price, Michael E., and Mark Van Vugt. 2014. “The Evolution of Leader-Follower Reciprocity: The Theory of Service-for-Prestige." Frontiers in Human Neuroscience 8: 363. doi:10.3389/fnhum.2014.00363.

Prooijen, Jan-Willem van. 2008. "Egocentrism in Procedural Justice Effects.” Advances in Group Processes 25 (December): 29-54. doi:10.1016/S0882-6145(08)25002-2.

Ramirez, Mark D. 2008. "Procedural Perceptions and Support for the U.S. Supreme Court." Political Psychology 29 (5): 675-98. doi:10.1111/j.1467-9221.2008.00660.x.

Rueden, Christopher von, Michael Gurven, Hillard Kaplan, and Jonathan Stieglitz. 2014. "Leadership in an Egalitarian Society." Human Nature 25 (4): 538-66. doi:10.1007/s12110-014-9213-4.

Schmitt, Manfred, and Martin Dörfel. 1999. "Procedural Injustice at Work, Justice Sensitivity, Job Satisfaction and Psychosomatic Well-Being.” European Journal of Social Psychology 29 (4): 443-53. doi:10.1002/(SICI)10990992(199906)29:4<443::AID-EJSP935>3.0.CO;2-C.

Schumpeter, J. A. 1943. Capitalism, Socialism and Democracy. New York: Routledge. Scott-Phillips, Thomas C., Thomas E. Dickins, and Stuart A. West. 2011. "Evolutionary Theory and the Ultimate-Proximate Distinction in the Human Behavioral Sciences.” Perspectives on Psychological Science 6 (1): 38-47. doi:10.1177/1745691610393528.

Sears, D. O., and C. L. Funk. 1991. "The Role of Self-Interest in Social and Political Attitudes." In Advances in Experimental Social Psychology, Zanna, M. P., 24:1-91. Academic Press. 
Sell, Aaron, John Tooby, and Leda Cosmides. 2009. "Formidability and the Logic of Human Anger." Proceedings of the National Academy of Sciences 106 (35): 15073-78. doi:10.1073/pnas.0904312106.

Sidanius, J, and F Pratto. 2001. Social Dominance: An Intergroup Theory of Social Hierarchy and Oppression. Cambridge: Cambridge University Press.

Smith, Heather J., Tom R. Tyler, Yuen J. Huo, Daniel J. Ortiz, and E. Allan. 1998. "The SelfRelevant Implications of the Group-Value Model: Group Membership, Self-Worth, and Treatment Quality.” Journal of Experimental Social Psychology 34 (5): 470-93. doi:10.1006/jesp.1998.1360.

Smith, Kevin B., Christopher W. Larimer, Levente Littvay, and John R. Hibbing. 2007. "Evolutionary Theory and Political Leadership: Why Certain People Do Not Trust Decision Makers.” The Journal of Politics 69 (02): 285-99. doi:10.1111/j.14682508.2007.00532.x.

Sweeney, Paul D., and Dean B. McFarlin. 1993. "Workers' Evaluations of the 'Ends' and the 'Means': An Examination of Four Models of Distributive and Procedural Justice." Organizational Behavior and Human Decision Processes 55 (1): 23-40. doi:10.1006/obhd.1993.1022.

Takenishi, Ako, and Masanori Takenishi. 1992. "Does Commitment Affect the Meaning of Fairness?: Commonality and Stability of Fairness Criteria in a Political Setting.” Social Justice Research 5 (4): 415-29. doi:10.1007/BF01050757.

Tetlock, Philip E. 2003. "Thinking the Unthinkable: Sacred Values and Taboo Cognitions.” Trends in Cognitive Sciences 7 (7): 320-24.

Thibaut, John W., and Laurens Walker. 1975. Procedural Justice: A Psychological Analysis. Lawrence Erlbaum Associates, Incorporated. 
Tooby, J, and L Cosmides. 1990. “The Past Explains the Present: Emotional Adaptations and the Structure of Ancestral Environments.” Ethology and Sociobiology 11: 375-424. 1992. “The Psychological Foundations of Culture.” In The Adapted Mind:

Evolutionary Psychology and the Generation of Culture, Barkow, J, L. Cosmides \& J. Tooby, 19-136. New York: Oxford University Press.

Tooby, J, L Cosmides, A Sell, D Lieberman, and D Sznycer. 2008. "Internal Regulatory Variables and the Design of Human Motivation: A Computational and Evolutionary Approach.” In Handbook of Approach and Avoidance Motivation, Elliot, A, 251-71.

Mahwah, NJ: Lawrence Erlbaum Associates.

Tooby, John, Leda Cosmides, and Michael E. Price. 2006. Cognitive Adaptations for NPerson Exchange: The Evolutionary Roots of Organizational Behavior.

Törnblom, Kjell Yngve, and Riël Vermunt. 2007. Distributive and Procedural Justice: Research and Social Applications. Ashgate Publishing, Ltd.

Trussler, Marc, and Stuart Soroka. 2014. "Consumer Demand for Cynical and Negative News Frames." The International Journal of Press/Politics 19 (3): 360-79. doi:10.1177/1940161214524832.

Turiel, E. 1983. The Development of Social Knowledge: Morality and Convention. Cambridge: Cambridge University Press.

Tyler, Tom, E. Allan Lind, Ken-Ichi Ohbuchi, Ikuo Sugawara, and Yuen J. Huo. 1998. "Conflict with Outsiders: Disputing within and Across Cultural Boundaries." Personality and Social Psychology Bulletin 24 (2): 137-46. doi:10.1177/0146167298242003.

Tyler, Tom R., and Andrew Caine. 1981. “The Influence of Outcomes and Procedures on Satisfaction with Formal Leaders." Journal of Personality and Social Psychology 41 (4): 642-55. doi:10.1037/0022-3514.41.4.642. 
Tyler, Tom R., and Peter Degoey. 1995. “Collective Restraint in Social Dilemmas:

Procedural Justice and Social Identification Effects on Support for Authorities." Journal of Personality and Social Psychology 69 (3): 482-97. doi:10.1037/00223514.69.3.482.

Tyler, Tom R., and E. Allan Lind. 1992. "A Relational Model of Authority in Groups." Advances in Experimental Social Psychology, 25 edition, sec. 25.

Tyler, T. R. 1990. Why People Obey the Law. Yale University Press. 1994. "Governing amid Diversity: The Effect of Fair Decisionmaking Procedures on the Legitimacy of Government." Law \& Society Review 28 (4): 809. doi: $10.2307 / 3053998$. - 1997. "The Psychology of Legitimacy: A Relational Perspective on Voluntary Deference to Authorities." Personality and Social Psychology Review: An Official Journal of the Society for Personality and Social Psychology, Inc 1 (4): 323-45. doi:10.1207/s15327957pspr0104_4.

Tyler, T. R., and Peter Degoey. 1996. "Trust in Organizational Authorities: The Influence of Motive Attributions on Willingness to Accept Decisions." In Trust in Organizations: Frontiers of Theory and Research, 1996th ed., 1996:331-57. Thousand Oaks, CA: SAGE.

Ulbig, Stacy G. 2002. "Policies, Procedures, and People: Sources of Support for Government?” Social Science Quarterly 83 (3): 789-809. doi:10.1111/15406237.00115.

Ulbig, Stacy G. 2008. "Voice Is Not Enough The Importance of Influence in Political Trust and Policy Assessments." Public Opinion Quarterly 72 (3): 523-39. doi:10.1093/poq/nfn030. 
Van den Bos, Kees, H. A. M. Wilke, and E. Allan. 1998. "When Do We Need Procedural Fairness? The Role of Trust in Authority." Journal of Personality and Social Psychology 75 (6): 1449-58. doi:10.1037/0022-3514.75.6.1449.

Van den Bos, Kees, H. A. M. Wilke, E. A. Lind, and Riël Vermunt. 1998. "Evaluating Outcomes by Means of the Fair Process Effect: Evidence for Different Processes in Fairness and Satisfaction Judgments.” Journal of Personality and Social Psychology 74 (6): 1493-1503. doi:10.1037/0022-3514.74.6.1493.

Van den Bos, K., E. A. Lind, R. Vermunt, and H. A. Wilke. 1997. "How Do I Judge My Outcome When I Do Not Know the Outcome of Others? The Psychology of the Fair Process Effect.” Journal of Personality and Social Psychology 72 (5): 1034-46. Van Dijke, Marius, David De Cremer, and David M. Mayer. 2010. “The Role of Authority Power in Explaining Procedural Fairness Effects.” Journal of Applied Psychology 95 (3): 488-502. doi:10.1037/a0018921.

Van Dijke, M., and P. Verboon. 2010. "Trust in Authorities as a Boundary Condition to Procedural Fairness Effects on Tax Compliance.” Journal of Economic Psychology 31 (1): 80-91. doi:10.1016/j.joep.2009.10.005.

Van Vugt, Mark. 2006. "Evolutionary Origins of Leadership and Followership.” Personality and Social Psychology Review 10 (4): 354-71.doi:10.1207/s15327957pspr1004_5. Van Vugt, Mark, Anjana Ahuja, and Mark Van Vugt. 2011. Naturally Selected: The Evolutionary Science of Leadership. New York: HarperBusiness.

Van Vugt, Mark, Robert Hogan, and Robert B Kaiser. 2008. "Leadership, Followership, and Evolution: Some Lessons from the Past.” The American Psychologist 63 (3): 182-96. doi:10.1037/0003-066X.63.3.182.

VanYperen, Nico W., Mariët Hagedoorn, Michiel Zweers, and Saapke Postma. 2000.

“Injustice and Employees’ Destructive Responses: The Mediating Role of State 
Negative Affect.” Social Justice Research 13 (3): 291-312. doi:10.1023/A:1026411523466.

Wade, Nicholas. 2007. Before the Dawn: Recovering the Lost History of Our Ancestors. New York, N.Y.: Penguin Books.

Weiss, Howard M., Kathleen Suckow, and Russell Cropanzano. 1999. "Effects of Justice Conditions on Discrete Emotions." Journal of Applied Psychology 84 (5): 786-94. doi:10.1037/0021-9010.84.5.786.

Whiten, Andrew, and Richard W. Byrne, eds. 1997. Machiavellian Intelligence II: Extensions and Evaluations. 2 edition. Cambridge ; New York, NY, USA: Cambridge University Press.

Wilking, Jennifer R. 2011. "The Portability of Electoral Procedural Fairness: Evidence from Experimental Studies in China and the United States." Political Behavior 33 (1): 13959. doi:10.1007/s11109-010-9119-8. 
Figure 1. Procedural fairness criteria.

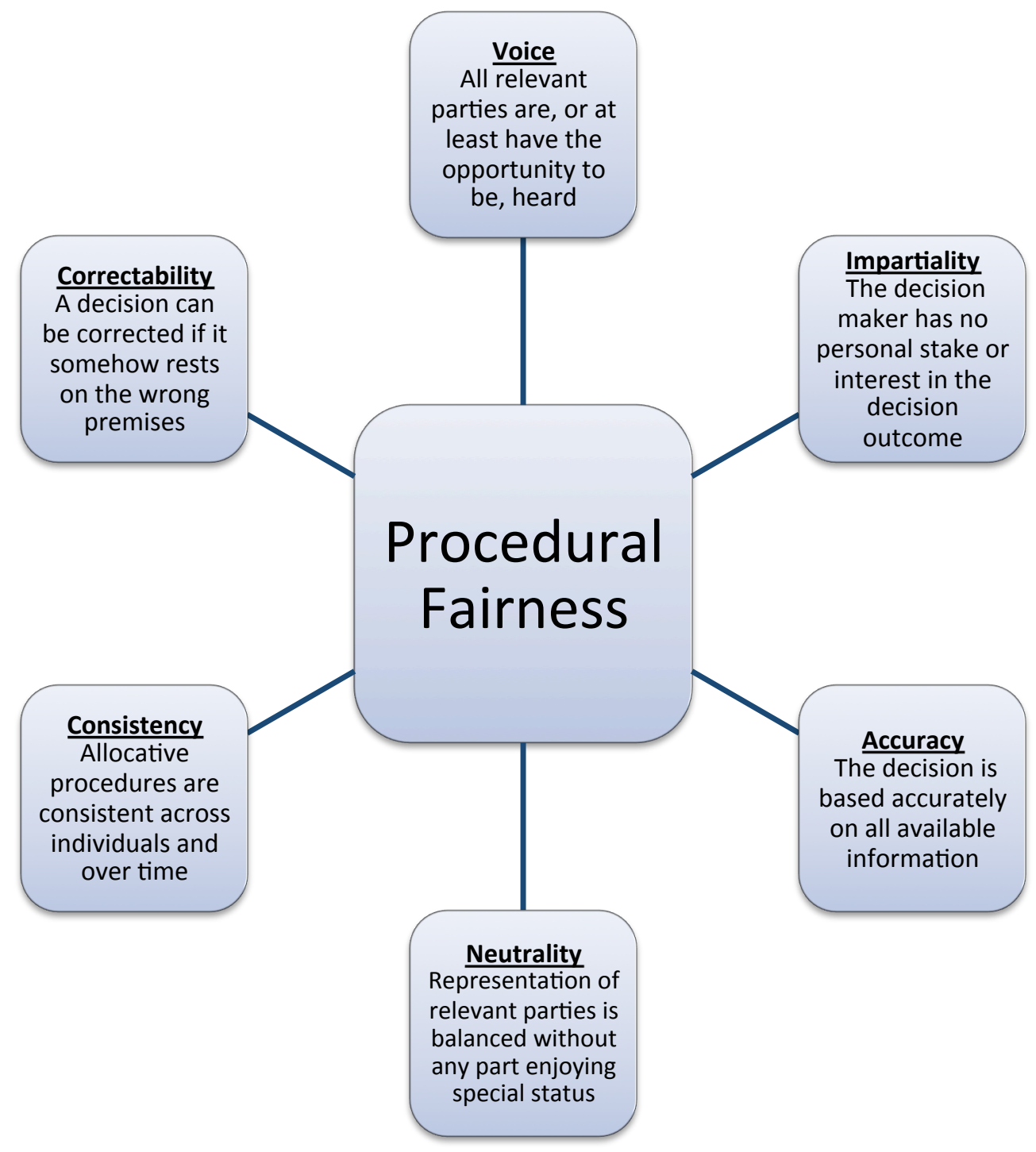

Note. The listed criteria reflect work by Leventhal (1980), Tyler (1990), Colquitt (2001) and Blader \& Tyler (2003). 